\title{
Cloning and Nucleotide Sequence Analysis of the Ampicillin Resistance Gene on a Conjugative R Plasmid from the Fish Pathogen Photobacterium damselae subsp. piscicida
}

\author{
HIDEAKI MORII* \\ Faculty of Fisheries, Nagasaki University, Bunkyou, Nagasaki 852-8521, Japan \\ Manish Surendra Bharadwaj And NaOya Eto \\ Graduate School of Science and Technology, Nagasaki University, \\ Bunkyou, Nagasaki 852-8521, Japan
}

\begin{abstract}
Transferable resistance to various drugs was investigated in strains of Photobacterium damselae subsp. piscicida from Japan. Drug resistance was transferred via two plasmids of 100 and 50 kilobases $(\mathrm{kb})$ or three plasmids of 100,50 , and $40 \mathrm{~kb}$. Resistance to ampicillin was transferred on the 50-kb plasmid. An ampicillin resistance gene in the 50-kb plasmid pPDP8517 from strain PP8517 was cloned from a 1.8-kb Hinc II fragment of the plasmid. The nucleotide sequence of the coding and flanking region of the ampicillin resistance gene was determined to be 1,736 base pairs. The nucleotide sequence identified an open reading frame (ORF) encoding 282 amino acid residues with a calculated molecular mass of 31,292 daltons. The ampicillin resistance gene's ORF was found to be a $\beta$-lactamase bearing low levels of amino acid identities $(<63 \%)$ relative to other $\beta$-lactamases. This ORF was very high in amino acid identities with class A $\beta$-lactamases compared with those of class B, C, and D $\beta$-lactamases. Four important structural features were conserved in all class A $\beta$-lactamases present in the deduced amino acid sequence of the ampicillin resistance gene. These results suggest that the $P$. damselae subsp. piscicida ampicillin resistance gene is a class A $\beta$-lactamase encoded on an $\mathrm{R}$ plasmid that is distinctly different from other known $\beta$-lactamases. Moreover, Southern blot analysis suggested that $P$. damselae strains with the ampicillin resistance gene are widely distributed in marine fish farms in the Kyushu area in Japan.
\end{abstract}

Photobacterium damselae subsp. piscicida (formerly Pasteurella piscicida; hereafter P. damselae) is the causative agent of pseudotuberculosis in cultured yellowtail Seriola quinqueradiata in Japan. Since its initial recognition in yellowtail during the summer of 1969 (Kubota et al. 1970), the disease has been recognized in other fish species, including blackhead seabream (also known as black porgy) Acanthopagrus schlegeli (Muroga et al. 1977; Ohnishi et al. 1982), red seabream (also known as madai) Pagrus major (Yasunaga et al. 1983), juvenile red grouper Epinephelus akaara (Ueki et al. 1990), juvenile striped jack (also known as white trevally) Caranx dentex (also known as Pseudocaranx dentex; Nakai et al. 1992), and juvenile flounder Paralichthys olivaceus (Fukuda et al. 1996). Various antimicrobial compounds have been used to prevent this infection by chemoprophylaxis and chemotherapy. The efficacy of these drugs, however, has been hindered by an increase in multiple drug resistance in $P$. damselae. Kusuda and Inoue (1976) reported that

\footnotetext{
* Corresponding author: morii@ net.nagasaki-u.ac.jp
}

Received October 24, 2003; accepted July 26, 2004 ampicillin had shown potent activity against $P$. damselae in vitro. Ampicillin has been used for treatment of pseudotuberculosis in cultured yellowtail in Japan since 1980. Ampicillin-resistant strains of $P$. damselae were found in large numbers after 1982 (Takashima et al. 1985; Kim and Aoki 1993). These bacterial strains did not transfer resistance to ampicillin (Takashima et al. 1985; Kim and Aoki 1993), with the exception of one of the many strains studied (Takashima et al. 1985). Therefore, it was suggested that resistance to ampicillin might be residing on the chromosomal DNA (Takashima et al. 1985; Kim and Aoki 1993). However, we reported that resistance to ampicillin was transferred via plasmids among many strains of P. damselae (Morii et al. 2003a, 2003b).

Bacterial resistance to ampicillin is conferred by the enzymes called $\beta$-lactamases (enzyme number 3.5.2.6; IUBMB 1992), which inactivate ampicillin by opening the $\beta$-lactam ring. These enzymes are divided into four molecular classes (A, B, C, and $\mathrm{D}$ ) on the basis of their primary structures. In many gram-negative bacteria, the structural gene for class $A \quad \beta$-lactamases is frequently plasmid contained. However, chromosomal genes encoding 
class A $\beta$-lactameses have been described for $V i b$ rio harveyi isolated from marine water near a shrimp farm (Teo et al. 2000) and for other bacteria (Yersinia [Seoane et al. 1991], Klebsiella [Haeggman et al. 1997], and Serratia spp. [Naas et al. 1994]). The genetic basis for $\beta$-lactam antibiotic resistance has not been studied for $P$. damselae isolated from farmed yellowtail. In this study, an ampicillin resistance gene on a transferable $\mathrm{R}$ plasmid from the $P$. damselae was cloned, and the nucleotide sequence of the resistance gene was obtained and compared with those previously reported. Nucleotide hybridization was performed to investigate the geographical and chronological distribution of the ampicillin resistance gene.

\section{Methods}

Bacteria and plasmids.-Photobacterium damselae were isolated from cultured diseased yellowtail in various areas of Kyushu, Japan, between 1984 and 1994. For isolation of the bacteria, the kidney was aseptically cultured directly on a brain-heart infusion (BHI) agar plate containing $2 \% \mathrm{NaCl}$. Replicate plates were incubated at $25^{\circ} \mathrm{C}$ for $24-48 \mathrm{~h}$. Isolated colonies were used for presumptive identification of the bacteria. The identification was carried out by means of the slide agglutination test (Roberson 1993) with rabbit antisera against $P$. damselae. The bacterial strains for this study were isolated from fish taken at various times and from several aquaculture locations. Several bacterial strains that were isolated at the same sampling time and location but that differed in their minimum inhibitory concentrations (MICs) of 14 drugs were also used. Overall, 111 strains of $P$. damselae were used for this study.

A total of 47 ampicillin-resistant isolates from the cultured diseased fish were used as donors for conjugal transfer of drug resistance genes. Strain PP8517, which harbored resistance to ampicillin, chloramphenicol, kanamycin, nalidixic acid, sulfamonomethoxine, and tetracycline, was used for cloning or nucleotide sequence analysis of an ampicillin resistance gene. A rifampicin-resistant mutant of Escherichia coli K-12 ×1037 (a mutant strain of X1037 [galK2, galT22, hsdR, lacY1, metB1, relA, supE44]; Iyobe et al. 1981, 1994) was used as the recipient for the conjugal transfer assay. Escherichia coli JM83 ( $F^{-}$, thi, ara, del [lacpro], strA [fi80, lacZ, del M15]) was used to obtain competent cells for transformation and also as the recipient for the retransfer assay. The $\mathrm{R}$ plasmid pPDP8517 from strain PP8517 was used as the source of the ampicillin resistance gene, and the vectors pHSG398 (chloramphenicol resistance, lacZ; Takara Shuzo, Siga, Japan) or pUC19 (ampicillin resistance, lacZ; Takara Shuzo) were used for cloning or nucleotide sequence analysis of the resistance gene.

Media and growth conditions.-Photobacterium damselae was incubated in BHI broth (Difco, Sparks, Nevada) containing $2 \% \mathrm{NaCl}$ at $28^{\circ} \mathrm{C}$ and E. coli in Luria-Bertani (LB) broth ( $1 \%$ bacto tryptone [Difco], $0.5 \%$ bacto yeast extract [Difco], and $1 \% \mathrm{NaCl} ; \mathrm{pH} 7.5)$ at $37^{\circ} \mathrm{C}$. Mueller-Hinton broth (Difco) containing $2 \% \mathrm{NaCl}$ and $1.5 \%$ agar was used for the drug susceptibility test. Bromothymol blue (BTB)-lactose nutrient agar (1\% bacto peptone [Difco], $1 \%$ beef extract [Difco], $1 \%$ lactose, $0.0045 \% \mathrm{BTB}, 0.5 \% \mathrm{NaCl}$, and $1.5 \%$ agar; $\mathrm{pH} 7.5$ ) was used for the mating assay.

Drug susceptibility test.-The drug susceptibility test was performed using Mueller-Hinton agar containing individual antibiotics and chemotherapeutants. Selected concentrations of drugs were prepared by a serial twofold dilution method recommended by the Japanese Society of Chemotherapy (1981). The culture was grown overnight in Mueller-Hinton broth and diluted to approximately $10^{6}$ cells $/ \mathrm{mL}$ using buffered saline with gelatin solution $\left(0.85 \% \mathrm{NaCl}, 0.03 \% \quad \mathrm{KH}_{2} \mathrm{PO}_{4}\right.$, $0.06 \% \mathrm{Na}_{2} \mathrm{HPO}_{4}$, and $0.01 \%$ gelatin) in accordance with the method of the Japanese Society of Chemotherapy (1981). The diluted culture was inoculated on Mueller-Hinton agar using a microplanter $(3 \mathrm{~mm}$ in diameter and $4 \mu \mathrm{L}$ per microplanter; Toyo Sokki, Tokyo, Japan). The MICs were read as the lowest concentration resulting in complete inhibition of growth after a $24-48 \mathrm{~h}$ incubation at $28^{\circ} \mathrm{C}$. The resistance to each antimicrobial compound was defined by the distribution of the MICs (see Figure 1). The following antibiotics and chemotherapeutics were employed for the drug susceptibility test: ampicillin, cephalexin, chloramphenicol, doxycycline, erythromycin, furazolidone, kanamycin, nalidixic acid, oxolinic acid, oxytetracycline, streptomycin, sulfamonomethoxine, tetracycline, and trimethoprim. The drug susceptibility of the transconjugants was tested using LB broth containing individual drugs. The ampicillin concentration was $50 \mu \mathrm{g} / \mathrm{mL}$ and those of the other drugs were as described below for the conjugal transfer assay. A strain was considered susceptible if its growth was completely inhibited after $24-48 \mathrm{~h}$ at $37^{\circ} \mathrm{C}$.

Conjugal transfer assay.-Each donor strain was incubated in the BHI broth (with shaking) for $9 \mathrm{~h}$ and the E. coli recipient strain was incubated in 


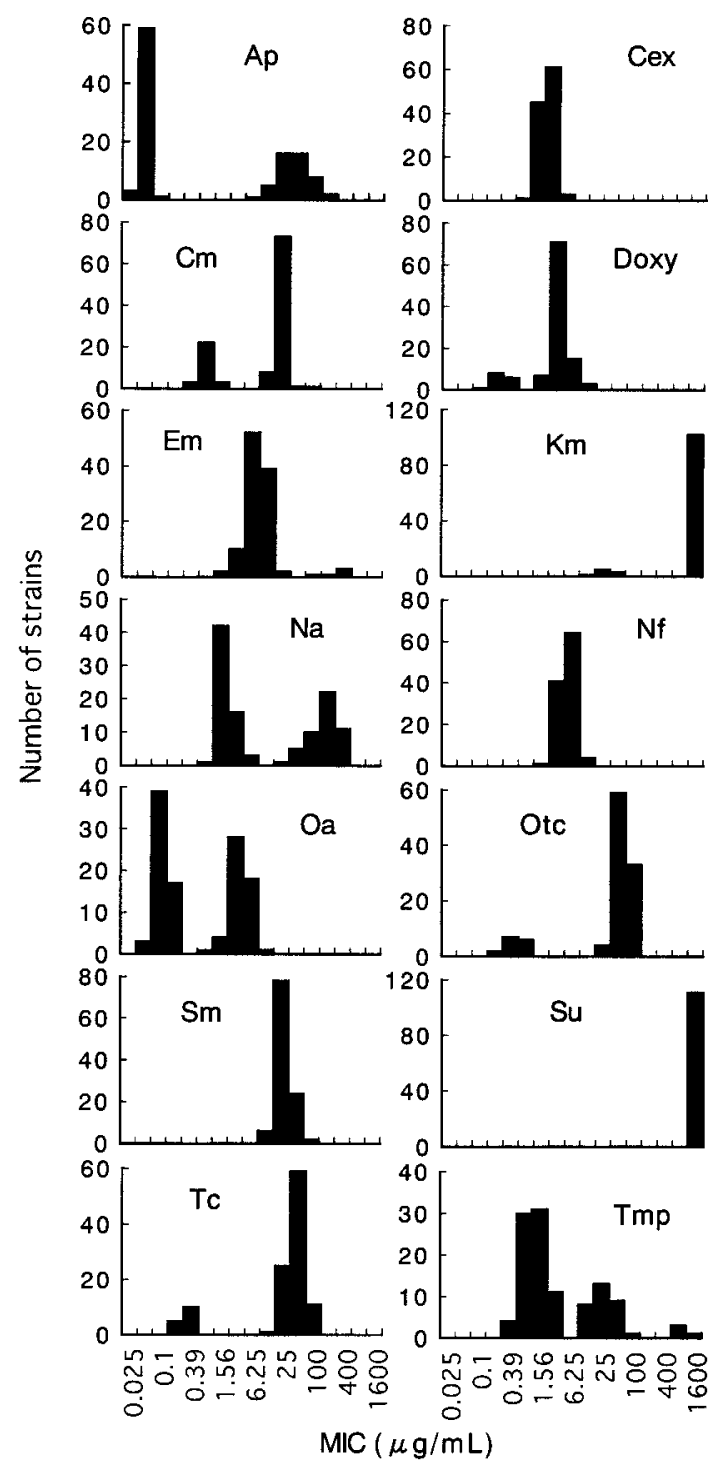

FIGURE 1.-Distributions of the minimum inhibitory concentrations (MICs) of 14 antimicrobial compounds in 111 strains of Photobacterium damselae subsp. piscicida isolated from cultured yellowtail. Compound abbreviations are as follows: Ap, ampicillin; Cex, cephalexin; Cm, chloramphenicol; Doxy, doxycycline; Em, erythromycin; Km, kanamycin; Na, nalidixic acid; Nf, furazolidone; Oa, oxolinic acid; Otc, oxytetracycline; $\mathrm{Sm}$, streptomycin; Su, sulfamonomethoxine; Tc, tetracycline; and Tmp, trimethoprim.

LB broth for $8 \mathrm{~h}$. Aliquots $(0.5 \mathrm{~mL}$ each $)$ of the donor and recipient cultures were mixed in a 50$\mathrm{mL}$ Erlenmeyer flask and $4 \mathrm{~mL}$ each of the BHI and LB broths were added to the flask. Mating was performed at $28^{\circ} \mathrm{C}$ for $2 \mathrm{~h}$. Of 10 -fold serial di- lutions of the mating mixture, $0.1 \mathrm{~mL}$ was spread on BTB-lactose agar with rifampicin $(50 \mu \mathrm{g} / \mathrm{mL})$ and each selected drug, namely, ampicillin (6.25 $\mu \mathrm{g} / \mathrm{mL})$, chloramphenicol $(25 \mu \mathrm{g} / \mathrm{mL})$, erythromycin $(100 \mu \mathrm{g} / \mathrm{mL})$, kanamycin $(25 \mu \mathrm{g} / \mathrm{mL})$, nalidixic acid $(100 \mu \mathrm{g} / \mathrm{mL})$, sulfamonomethoxine $(3,200 \mu \mathrm{g} / \mathrm{mL})$, tetracycline $(25 \mu \mathrm{g} / \mathrm{mL})$, and trimethoprim $(400 \mu \mathrm{g} / \mathrm{mL})$. The concentration of ampicillin was $100 \mu \mathrm{g} / \mathrm{mL}$ in an earlier study (Morii et al. 2003a) but $6.25 \mu \mathrm{g} / \mathrm{mL}$ in this study because an ampicillin resistance gene in the transconjugants selected in the mating experiment was frequently deleted at higher concentrations of ampicillin. The E. coli recipient strain expressed MIC values as follows: ampicillin $(3.13 \mu \mathrm{g} / \mathrm{mL})$, chloramphenicol $(12.5 \mu \mathrm{g} / \mathrm{mL})$, erythromycin $(50 \mu \mathrm{g} /$ $\mathrm{mL})$, kanamycin $(12.5 \mu \mathrm{g} / \mathrm{mL})$, nalidixic acid (50 $\mu \mathrm{g} / \mathrm{mL})$, sulfamonomethoxine $(1,600 \mu \mathrm{g} / \mathrm{mL})$, tetracycline $(6.25 \mu \mathrm{g} / \mathrm{mL})$, and trimethoprim $(12.5$ $\mu \mathrm{g} / \mathrm{mL})$. Colonies growing after $24-48 \mathrm{~h}$ of incubation at $37^{\circ} \mathrm{C}$ were scored as presumptive transconjugants, and the frequency of transfer was calculated as the number of transconjugants per initial number of donors. Ten or more transconjugants from mating were picked and tested for antibiotic resistance. The transconjugants from mating with the donor strain PP8517 were also used for isolation of $\mathrm{R}$ plasmids.

Plasmid manipulation and characterization.- $\mathrm{R}$ plasmids were extracted by the method of Kado and Liu (1981) and electrophoresed on a $0.7 \%$ agarose gel. Plasmid DNA was prepared by rapid alkaline lysis and cesium chloride-ethidium bromide density gradient purification. Restriction-endonuclease-digested DNA was electrophoresed on a 1.0\% low-melting-temperature agarose gel (Grosa et al. 1994) for separation of the DNA fragments. Restriction endonucleases and T4 DNA ligase (enzyme number 6.5.1.1; IUBMB 1992) were purchased from Takara Shuzo and used according to the manufacturer's instructions.

The approximate molecular sizes of plasmids were calculated from reference plasmids R27 (167 kilobases [kb]), R100-1 (100 kb), RP4 (56 kb), and pLA2917 $(22 \mathrm{~kb})$. The molecular sizes of restriction fragments were calculated using $\lambda$ DNA digested with Sty I (Nippon Gene, Toyama, Japan).

Nucleotide hybridization.-The procedure for Southern blotting was taken from the instructions given in the digoxigenin application manual for filter hybridization (Roche Molecular Biochemicals, Mannheim, Germany), DIG Oligonucleotide $3^{\prime}$-End Labeling Kit, 2nd Generation except that the depurination was carried out for $10 \mathrm{~min}$. Plas- 
mid DNA from the gels was capillary blotted onto nylon hybridyzation membranes (Hybond-N+; Amersham, Piscataway, New Jersey) and fixed at $120^{\circ} \mathrm{C}$ for $30 \mathrm{~min}$. Oligonucleotides (5'-GCTGA TGACCTACGTGATACAACGACGCCATTTGC GATGA-3'), which were designed on the basis of the nucleotide sequence of the pPDP8517 ampicillin resistance gene, were enzymatically labeled at their $3^{\prime}$ end with terminal transferase by incorporation of a single digoxigenin-labeled dideoxyuridine triphosphate. Hybridization was performed at $55^{\circ} \mathrm{C}$ for $4 \mathrm{~h}$ as prescribed by the manufacturer.

Cloning of the ampicillin resistance gene.- $\mathrm{Nu}$ cleic acid from the plasmid pPDP8517 was completely digested with the restriction endonuclease Hinc II. The resulting fragments were cloned into the Hinc II site of the vector pHSG398. Competent E. coli JM83 cells prepared according to the method of Hanahan (1983) were transformed with the recombinant plasmid DNA by the procedure of Lederberg and Cohen (1974). Clones harboring the ampicillin resistance gene were selected on LB agar plates containing either chloramphenicol alone $(25 \mu \mathrm{g} / \mathrm{mL})$ or ampicillin $(50 \mu \mathrm{g} / \mathrm{mL})$ in combination with chloramphenicol $(25 \mu \mathrm{g} / \mathrm{mL})$ and X-gal (5-bromo-4-chloro-3-indolyl- $\beta$-D-galactopyranoside; Takara Shuzo) and isopropyl-FID-thio-galactopyranoside. The recombinant DNA insert was digested with Hinc II and was subcloned into the Hinc II site of the vector pUC19. Recombinant plasmid containing the ampicillin resistance gene was used as the source of the gene and flanking sequences.

Nucleotide sequencing and analysis.-The subcloned fragment containing the ampicillin resistance gene was sequenced by the dideoxy chain termination method using a BigDye Terminator Cycle Sequencing Kit and an ABI 377 DNA sequencer (Applied Biosystems, Foster, California) . Nucleic acid sequencing was performed using M13 forward and reverse primers. Internal sequencing primers (primer sequences5'-TCCGGC TGCTACCCTTTCGA-3' and 5'-GCTACAGGAC TCTGATAGAG-3') were designed on the basis of the sequence of the subcloned fragment to complete the sequence walk in both directions. The nucleotide sequence of the ampicillin resistance gene was analyzed with version 3.6 of DNASISMac software (Hitachi Software Engineering, Chiba, Japan). Sequence similarity and homology searching against the nucleotide and deduced protein databases were carried out with the Fasta programs at the European Molecular Biology Labo- ratory, European Bioinformatics Institute (EMBLEBI). Multiple-sequence alignment of the deduced peptide sequence was performed with the Clustal $\mathrm{W}$ programs at EMBL-EBI. The identification of signal peptides was carried out with version 1.1 of the program SignalP at the Center for Biological Sequence Analysis. $\beta$-lactamases belonging to individual structural classes were searched at the $\mathrm{Na}$ tional Center for Biotechnology Information Web site, and the class of various $\beta$-lactamases was determined from the fold classification based on the structure-structure alignment of proteins database at EMBL-EBL.

\section{Results}

\section{MIC Distribution of Antimicrobial Compounds}

The distributions of the MICs of 14 antimicrobial compounds for 111 strains of $P$. damselae are shown in Figure 1. The MIC distribution exhibited either three groups (susceptible, intermediate-level resistant, and high-level resistant), two groups (susceptible and resistant), or a single group in which all the tested strains were susceptible to cephalexin, furazolidone, and streptomycin while resistant to sulfamonomethoxine. Additionally, the resistant strains were found to be identical in the chemically related drugs doxycycline, oxytetracycline, and tetracycline or nalidixic acid and oxolinic acid.

\section{Conjugal Transfer of Drug Resistance}

The drug resistance patterns (different combinations of drug resistance markers) of the $P$. damselae isolates and the recipient $E$. coli strains are shown in Table 1. Forty-seven $(42 \%)$ of the 111 isolates studied harbored resistance to ampicillin. The different multidrug resistance patterns for the 47 strains were numbered 1-6; all strains were resistant to 5-8 drugs. All 47 strains were resistant to sulfamonomethoxine, kanamycin, and chloramphenicol, while 46 were also resistant to tetracycline.

Forty-one $(87 \%)$ of the 47 ampicillin-resistant strains transferred the resistance from the donor to the recipient. Resistance to ampicillin was transferred from all the strains in patterns 2-6 (which were resistant to nalidixic acid and/or trimethoprim), but resistance was not transferred from the strains in pattern 1 (sensitive to nalidixic acid and/ or trimethoprim). Resistance to trimethoprim was not transferred in all the strains because the resistance was not high-level (the transfer of trimethoprim resistance was restricted to strains harboring high-level resistance, though the reason for this is 
TABLE 1.-Drug resistance pattern of Photobacterium damselae subsp. piscicida isolates harboring resistance to ampicillin (the donor) and drug resistance transferred to an Escherichia coli K-12 $\chi 1037$ rifampicin-resistant strain (the recipient). The drugs used for the conjugal transfer assay were ampicillin (Ap), chloramphenicol (Cm), erythromycin $(\mathrm{Em})$, kanamycin $(\mathrm{Km})$, nalidixic acid $(\mathrm{Na})$, sulfamonomethoxine $(\mathrm{Su})$, tetracycline $(\mathrm{Tc})$, and trimethoprim (Tmp).

\begin{tabular}{clcccr}
\hline & \multicolumn{2}{c}{ Donor } & & & \multicolumn{2}{c}{ Recipient } \\
\cline { 2 - 3 } \cline { 5 - 6 } $\begin{array}{c}\text { Pattern } \\
\text { no. }\end{array}$ & \multicolumn{1}{c}{$\begin{array}{c}\text { Drug resistance } \\
\text { pattern }\end{array}$} & $\begin{array}{c}\text { No. of } \\
\text { strains }\end{array}$ & & $\begin{array}{c}\text { Drug resistance } \\
\text { pattern }\end{array}$ & $\begin{array}{c}\text { No. of } \\
\text { strains }\end{array}$ \\
\hline 1 & $\mathrm{Su}, \mathrm{Km}, \mathrm{Tc}, \mathrm{Cm}, \mathrm{Ap}$ & 11 & & $\mathrm{Su}, \mathrm{Km}, \mathrm{Tc}, \mathrm{Cm}$ & 6 \\
& & & & $\mathrm{Su}, \mathrm{Km}, \mathrm{Tc}, \mathrm{Cm}, \mathrm{Ap}$ & 5 \\
2 & $\mathrm{Su}, \mathrm{Km}, \mathrm{Tc}, \mathrm{Cm}, \mathrm{Ap}, \mathrm{Na}$ & 12 & & $\mathrm{Su}, \mathrm{Km}, \mathrm{Tc}, \mathrm{Cm}, \mathrm{Ap}$ & 12 \\
3 & $\mathrm{Su}, \mathrm{Km}, \mathrm{Tc}, \mathrm{Cm}, \mathrm{Ap}, \mathrm{Tmp}$ & 2 & & $\mathrm{Su}, \mathrm{Km}, \mathrm{Tc}, \mathrm{Cm}, \mathrm{Ap}$ & 2 \\
4 & $\mathrm{Su}, \mathrm{Km}, \mathrm{Cm}, \mathrm{Ap}, \mathrm{Na}, \mathrm{Tmp}$ & 1 & & $\mathrm{Su}, \mathrm{Km}, \mathrm{Cm}, \mathrm{Ap}$ & 1 \\
5 & $\mathrm{Su}, \mathrm{Km}, \mathrm{Tc}, \mathrm{Cm}, \mathrm{Ap}, \mathrm{Na}, \mathrm{Tmp}$ & 19 & & $\mathrm{Su}, \mathrm{Km}, \mathrm{Tc}, \mathrm{Cm}, \mathrm{Ap}$ & 19 \\
6 & $\mathrm{Su}, \mathrm{Km}, \mathrm{Tc}, \mathrm{Cm}, \mathrm{Ap}, \mathrm{Em}, \mathrm{Na}$, & 2 & & $\mathrm{Su}, \mathrm{Km}, \mathrm{Tc}, \mathrm{Cm}, \mathrm{Ap}, \mathrm{Em}$ & 2 \\
& $\mathrm{Tmp}$ & & & & \\
\hline
\end{tabular}

not clear; Morii et al. 2003a). Additionally, only one transconjugant from each mating with the donors PP8517 and PP9303 was obtained on the selection media containing nalidixic acid. However, the transconjugants did not harbor a plasmid. Moreover, in the secondary matings with the transconjugants and E. coli JM83 strain as the recipient, transconjugants were not obtained on the selection media containing nalidixic acid.

\section{Plasmid Phenotypes}

The drug resistance of transconjugants obtained from matings between the donor $P$. damselae and the recipient $E$. coli strains as well as the plasmid content of the transconjugants and their transfer frequency are shown in Table 2; agarose gel electrophoretic profiles of the $\mathrm{R}$ plasmids in the transconjugants are shown in Figure 2. Conjugal transfer of ampicillin resistance was usually unstable in matings between the donor and recipient strains; that is, resistance to ampicillin was transferred at random from almost all the donor strains. Moreover, resistance to ampicillin was transferred (experiment I) or not transferred (experiment II) in the repeated-mating assay between the same donor and recipient. All transferable drug resistances present in each of the donors were transferred via a single plasmid of $100 \mathrm{~kb}$ when resistance to ampicillin was not transferred (experiment II). Ampicillin resistance was most closely associated with the transfer of a 50-kb plasmid, although ampicillin resistance appeared to occasionally be harbored simultaneously on a $110-\mathrm{kb}$ plasmid (patterns 1 [2], 2, 4, and 5). The plasmids of 100 and $40 \mathrm{~kb}$ were also present, but they did not harbor an ampicillin resistance gene.

The drug resistance encoded on these plasmids usually varied among drug resistance patterns, that is, (1) the sulfamonomethoxine and kanamycin resistances of the donors were transferred via the $100-\mathrm{kb}$ plasmid and the other resistances via the $50-\mathrm{kb}$ plasmid (patterns 4 and 5) or both the 50$\mathrm{kb}$ and $40-\mathrm{kb}$ plasmids (pattern 6); (2) the sulfamonomethoxine, kanamycin, and tetracycline resistances of the donors were transferred via the $100-\mathrm{kb}$ plasmid and the other resistances via the $50-\mathrm{kb}$ plasmid (patterns 2 and 3); and (3) the conjugal transfer of drug resistances from the donors was complicated (pattern 1). Some drug resistance present in each donor was transferred via both the $100-\mathrm{kb}$ and $50-\mathrm{kb}$ plasmids. Trasconjugants from the transfer assay harbored a single plasmid of 100 , 50 , and $40 \mathrm{~kb}$ each or two plasmids of 100 and 50 or $40 \mathrm{~kb}$ (see Figure 2). Transconjugants that harbored both of the $100-\mathrm{kb}$ and $50-\mathrm{kb}$ plasmids occasionally possessed the $110-\mathrm{kb}$ plasmid simultaneously (see lane E in Figure 2), which harbored all of the drug resistances encoding on both the plasmids.

The transfer frequency of the $100-\mathrm{kb}$ plasmid was usually higher than that of the $50-\mathrm{kb}$ or $40-$ $\mathrm{kb}$ plasmids, but the frequency could not be determined when more than one other plasmid was transferred along with the 110-kb plasmid.

\section{Nucleotide Sequence Analysis}

The subcloned Hinc II fragment of pPDP8517 was determined as being 1,736 base pairs (bp; DNA Databank of Japan [DDBJ] under accession number AB083415). The ampicillin resistance gene ORF was identified from nucleotides 1831,028 in the subcloned pPDP8517 DNA fragment. The ampicillin resistance gene was predicted to contain 282 amino acid residues and has been estimated to have a molecular mass of 31,292 daltons, a size that is consistent with those of the other 
TABLE 2.-Drug resistance of transconjugants from representative matings between donor strains showing different resistance patterns and recipient strains, plasmid content of the transconjugants, and transfer frequency of the resistances. Drugs used for the mating assay were ampicillin (Ap), chloramphenicol (Cm), erythromycin (Em), kanamycin (Km), nalidixic acid $(\mathrm{Na})$, sulfamonomethoxine $(\mathrm{Su})$, tetracycline $(\mathrm{Tc})$, and trimethoprim (Tmp). Resistance to ampicillin was transferred (experiment I) or not transferred (experiment II) by repeating matings between the same donors and recipients.

\begin{tabular}{|c|c|c|c|c|c|c|c|c|c|c|c|c|c|}
\hline \multirow{2}{*}{$\begin{array}{c}\text { Drug } \\
\text { resis- } \\
\text { tance } \\
\text { patterna }\end{array}$} & \multirow{2}{*}{$\begin{array}{c}\text { Donor } \\
\text { strain }\end{array}$} & \multirow{2}{*}{$\begin{array}{c}\text { Experi- } \\
\text { ment }\end{array}$} & \multirow[b]{2}{*}{ Transconjugant ${ }^{\mathrm{b}}$} & \multicolumn{8}{|c|}{ Drug resistance of transconjugants ${ }^{c}$} & \multirow{2}{*}{$\begin{array}{c}\text { Plasmid } \\
\text { content } \\
\text { of trans- } \\
\text { conju- } \\
\text { gants }(\mathrm{Kb})\end{array}$} & \multirow{2}{*}{$\begin{array}{l}\text { Transfer } \\
\text { frequency of } \\
\text { resistance }\end{array}$} \\
\hline & & & & $\mathrm{Su}$ & $\mathrm{Km}$ & $\mathrm{Tc}$ & $\mathrm{Cm}$ & Ap & Em & $\mathrm{Na}$ & Tmp & & \\
\hline \multirow[t]{4}{*}{$1(1)$} & PP8521 & I & $\mathrm{Su}, \mathrm{Tc}, \mathrm{Cm}$ & + & - & + & + & - & nd & nd & nd & 100 & $10^{-3}$ \\
\hline & & & $\mathrm{Km}, \mathrm{Ap}$ & - & + & + & - & + & nd & nd & nd & 50 & $\mathrm{Km}: 10^{-5} ; \mathrm{Ap}: 10^{-3}$ \\
\hline & & & $\mathrm{Km}$ & + & + & + & + & + & nd & nd & nd & $100+50$ & nd \\
\hline & PP8521 & II & $\mathrm{Su}, \mathrm{Km}, \mathrm{Tc}, \mathrm{Cm}$ & + & + & + & + & - & nd & nd & nd & 100 & $10^{-3}$ \\
\hline \multirow[t]{5}{*}{$1(2)$} & PP8808 & I & $\mathrm{Su}, \mathrm{Km}, \mathrm{Tc}, \mathrm{Cm}$ & + & + & + & + & - & nd & nd & nd & 100 & $10^{-2}$ \\
\hline & & & Ap & + & - & - & - & + & nd & nd & nd & 50 & $10^{-4}$ \\
\hline & & & Ap & + & + & + & + & + & nd & nd & nd & $100+50$ & nd \\
\hline & & & Ap & + & + & + & + & + & nd & nd & nd & 110 & nd \\
\hline & PP8808 & II & $\mathrm{Su}, \mathrm{Km}, \mathrm{Tc}, \mathrm{Cm}$ & + & + & + & + & - & nd & nd & nd & 100 & $10^{-2}$ \\
\hline \multirow[t]{5}{*}{2} & PP8517 & I & $\mathrm{Su}, \mathrm{Km}, \mathrm{Tc}$ & + & + & + & - & - & nd & - & nd & 100 & $10^{-4}$ \\
\hline & & & $\mathrm{Cm}, \mathrm{Ap}$ & - & - & - & + & + & nd & - & nd & 50 & $10^{-6}$ \\
\hline & & & $\mathrm{Cm}, \mathrm{Ap}$ & + & + & + & + & + & nd & - & nd & $100+50$ & nd \\
\hline & & & $\mathrm{Cm}, \mathrm{Ap}$ & + & + & + & + & + & nd & - & nd & 110 & nd \\
\hline & PP8517 & II & $\mathrm{Su}, \mathrm{Km}, \mathrm{Tc}, \mathrm{Cm}$ & + & + & + & + & - & nd & - & nd & 100 & $10^{-4}$ \\
\hline \multirow[t]{4}{*}{3} & PP8836 & I & $\mathrm{Su}, \mathrm{Km}, \mathrm{Tc}$ & + & + & + & - & - & nd & nd & - & 100 & $10^{-3}$ \\
\hline & & & $\mathrm{Cm}, \mathrm{Ap}$ & - & - & - & + & + & nd & nd & - & 50 & $10^{-5}$ \\
\hline & & & $\mathrm{Cm}, \mathrm{Ap}$ & + & + & + & + & + & nd & nd & - & $100+50$ & nd \\
\hline & PP8836 & II & $\mathrm{Su}, \mathrm{Km}, \mathrm{Tc}, \mathrm{Cm}$ & + & + & + & + & - & nd & nd & - & 100 & $10^{-3}$ \\
\hline \multirow[t]{5}{*}{4} & PP8912 & I & $\mathrm{Su}, \mathrm{Km}$ & + & + & nd & - & - & nd & - & - & 100 & $10^{-4}$ \\
\hline & & & $\mathrm{Cm}, \mathrm{Ap}$ & - & - & nd & + & + & nd & - & - & 50 & $10^{-6}$ \\
\hline & & & $\mathrm{Cm}, \mathrm{Ap}$ & + & + & nd & + & + & nd & - & - & $100+50$ & nd \\
\hline & & & $\mathrm{Cm}, \mathrm{Ap}$ & + & + & nd & + & + & nd & - & - & 110 & nd \\
\hline & PP8912 & II & $\mathrm{Su}, \mathrm{Km}, \mathrm{Cm}$ & + & + & nd & + & - & nd & - & - & 100 & $10^{-4}$ \\
\hline \multirow[t]{5}{*}{5} & PP9303 & I & $\mathrm{Su}, \mathrm{Km}$ & + & + & - & - & - & nd & - & - & 100 & $10^{-5}$ \\
\hline & & & $\mathrm{Tc}, \mathrm{Cm}, \mathrm{Ap}$ & - & - & + & + & + & nd & - & - & 50 & $10^{-7}$ \\
\hline & & & $\mathrm{Tc}, \mathrm{Cm}, \mathrm{Ap}$ & + & + & + & + & + & nd & - & - & $100+50$ & nd \\
\hline & & & $\mathrm{Tc}, \mathrm{Cm}, \mathrm{Ap}$ & + & + & + & + & + & nd & - & - & 110 & nd \\
\hline & PP9303 & I & $\mathrm{Su}, \mathrm{Km}, \mathrm{Tc}, \mathrm{Cm}$ & + & + & + & + & - & nd & - & - & 100 & $10^{-5}$ \\
\hline \multirow[t]{5}{*}{6} & PP9105 & I & $\mathrm{Su}, \mathrm{Km}$ & + & + & - & - & - & - & - & - & 100 & $10^{-3}$ \\
\hline & & & $\mathrm{Tc}, \mathrm{Cm}, \mathrm{Ap}$ & - & - & + & + & + & - & - & - & 50 & $10^{-6}$ \\
\hline & & & $\mathrm{Tc}, \mathrm{Cm}, \mathrm{Ap}$ & + & + & + & + & + & - & - & - & $100+50$ & nd \\
\hline & & & $\mathrm{Cm}, \mathrm{Em}$ & - & - & - & + & - & + & - & - & 40 & $10^{-6}$ \\
\hline & & & $\mathrm{Cm}, \mathrm{Em}$ & + & + & - & + & - & + & - & - & $100+40$ & nd \\
\hline
\end{tabular}

a The experiment was performed for all of the tested strains and the results are presented for one strain in each of the resistance patterns 2 to 6 and for two strains in pattern 1 .

${ }^{b}$ Indicated by the drug with which it was selected.

c Plus signs indicate resistant transconjugants and minus signs susceptible ones; nd $=$ not determined.

known class A $\beta$-lactamases (Ambler 1980). The first base of the heptanucleotide 5'-AGTCGAG3 ', which represents the consensus prokaryotic ribosome binding site, occurs 12 nucleotides upstream of the ATG translational start codon. Nucleotide sequences within the $5^{\prime}$ and $3^{\prime}$ noncoding regions represent consensus motifs for the initiation and termination of transcription, namely, the-35 sequence $\left(5^{\prime}\right.$-TTGATT- $3^{\prime}$ from nucleotides 73-68 upstream of the ATG) and-10 (Pribnow box) sequence (5'-TATTAT-3' from nucleotides 51-46 upstream of the ATG), respectively.

The alignments of the amino acid sequence of the $P$. damselae ampicillin resistance gene and the sequences of class A $\beta$-lactamases from nine other bacteria, which showed high homology to the sequences of class A $\beta$-lactamases, are shown in Figure 3 . The alignments revealed that a total of 60 amino acid residues were conserved in all the aligned sequences. The pPDP8517 ampicillin resistance gene ORF (accession number AB083415) showed a maximum of $63 \%$ amino acid identity with a $\beta$-lactamase found in Vibrio marinus (BAA89386) and 56-40\% identities with $\beta$-lactamases from another bacteria (gram negative).

Four important structural features found con- 


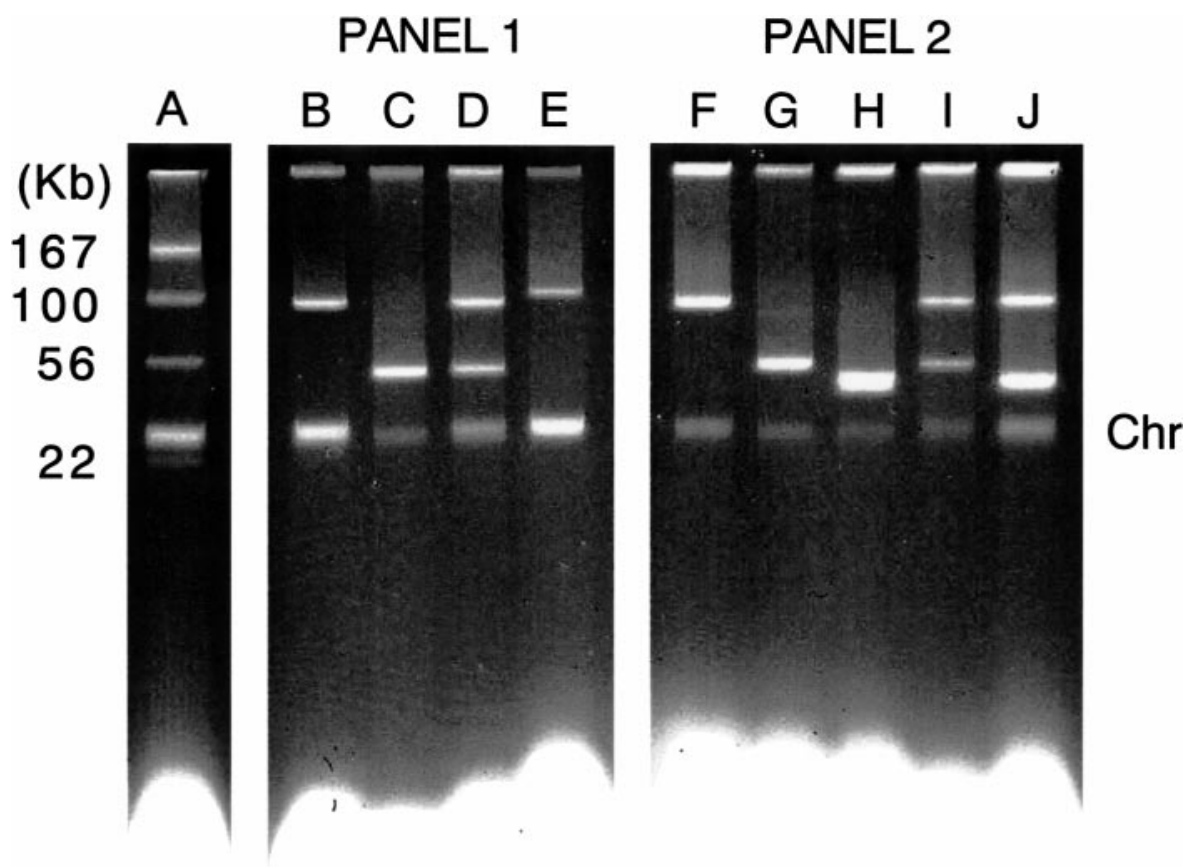

FIGURE 2.-Agarose gel electrophoresis of R plasmids in transconjugants selected with articular drugs in matings with the donor Photobacterium damselae subsp. piscicida strains PP8517 (panel 1) and PP9105 (panel 2) and the rifampicin-resistant recipient, Escherichia coli K-12 $\chi 1037$. Lane A shows the molecular sizes of reference plasmids (R27 [167 kb], R100-1 [100 kb], RP4 [56 kb], and pLA2917 [22 kb]); lane B shows the 100-kb plasmid in a transconjugant selected with either kanamycin, sulfamonomethoxine, or tetracycline; lanes $\mathrm{C}-\mathrm{E}$ show the 50-kb, the 100 - and $50-\mathrm{kb}$, and the $110-\mathrm{kb}$ plasmids, respectively, in transconjugants selected with either ampicillin or chloramphenicol; lane F shows the 100-kb plasmid in a transconjugant selected with either kanamycin or sulfamonomethoxine; lanes $\mathrm{G}$ and I show the $100-\mathrm{kb}$ and the 100 - and $50-\mathrm{kb}$ plasmids, respectively, in transconjugants selected with either ampicillin, chloramphenicol, or tetracycline; lanes $\mathrm{H}$ and $\mathbf{J}$ show the 40-kb and the 100- and 40-kb plasmids, respectively, in transconjugants selected with either chloramphenicol or erythromycin. The abbreviation Chr stands for chromosomal DNA.

served in class A $\beta$-lactamases (Ambler 1980; Matagne and Frere 1995) were present in the deduced amino acid sequence of the pPDP8517 ampicillin resistance gene, which included a serine-threonine-phenylalanine-lysine (STFK) active site tetrad at position 70-73 according to Ambler's standard numbering of class A $\beta$-lactamases (Ambler 1980; Ambler et al. 1991). This serine-X-X-lysine tetrad is reported to be characteristic of serine $\beta$ lactamases (Joris et al. 1991). A serine-asparatic acid-asparagine (SDN) triad reported as characteristic of a class A $\beta$-lactamase was located at position 130-132. An RSG triad was established at position 234-236. Normally, the triad at this position is a lysine-threonine-glycine (KTG) for the other serine $\beta$-lactamases (classes $C$ and $D$ ) and the RSG substitution (if seen) is only in class A $\beta$-lactamases. Lastly, 16 amino acid residues usually referred to as the $\Omega$-loop were present at position 164 (arginine) to 179 (asparatic acid) and contained the unique glutamic acid residue at position 166.

The pPDP8517 ampicillin resistance gene ORF was very low in amino acid identities with classes $\mathrm{B}, \mathrm{C}$, and $\mathrm{D} \beta$-lactamases (9-1\%) compared with the identities with class A $\beta$-lactamases (63-40\%). Moreover, the amino acid residues conserved in all the aligned sequences were not found among the amino acid sequence of the $P$. damselae ampicillin resistance gene and the sequences of class $\mathrm{B}, \mathrm{C}$, and $\mathrm{D} \beta$-lactamases.

\section{Distribution of pPDP8517 Ampicillin Resistance Gene in Other P. damselae Isolates}

The 40-bp fragment from the pPDP8517 ampicillin resistance gene was used to probe against transferable $\mathrm{R}$ plasmids from 41 other $P$. damselae isolates (Figure 4). Hybridization occurred at the $50-\mathrm{kb}$ plasmid (see lanes $\mathrm{A}-\mathrm{G}$ and $\mathrm{I}-\mathrm{O}$ ) in the 40 strains isolated from various areas and years. No 
$\mathrm{AB} 083415$

BAA89386

AAF 23817

AAD19217

AAB19430

AAK02055

AAL 85333

AAC09015

BAA02496

AAF61417

$A B 083415$

BAA89386

AAF 23817

AAD19217

AAB 19430

AAK02055

AAL 85333

AACO9015

BAA02496

AAF61417

AB083415

BAA89386

AAF23817

AAD19217

AAB19430

AAK02055

AAL 85333

AAC09015

BAA02496

AAF61417

$A B 083415$

BAA89386

AAF23817

AAD19217

AAB19430

AAKO2055

AAL 85333

AAC09015

BAA02496

AAF61417

$\mathrm{AB} 083415$

BAA89386

AAF23817

AAD19217

AAB19430

AAK02055

AAL 85333

AACO9015

BAA02496

AAF61417

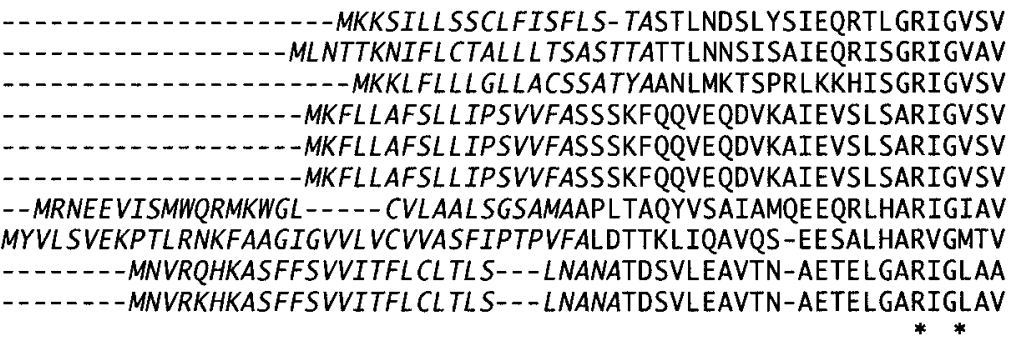

70

LDS-TDQQWHYKGNERFPMMVIVITLACAKMLQDSDRDILDISTMAPVKSDELIAWSPITKNM LDTQNKQTWAYNGDAHFPMMYIVI ILACAKMLSESTNGNLDPSTSSLIKAEELIPWSPVTKTF WDTQTDEHWDYRGDERFPMM \% \% KLACATML SDMDNEKLDKNATAKVEERNMVVWSPVMDRM LDTQNGEYWDYNGNQRFPLTS Y ITACAKLLYDAEQGKVNPNSTVEIKKADLVTYSPVIEKQ LDTQNGEYWDYNGNQRFPLTS \% I IACAKLLYDAEQGKVNPNSTVEIKKADLVTYSPVIEKQ LDTQNGEYWDYNGNQRFPLT. LDTATNSITHYRGEERFPLN FDSNTGTTWNYRGDERFPLN \& I XTFSCAALLAKVDGKSLSLGQSVSISKEMLVTYSPITEKS HDLETGKRWEHKSNERFPLS \% HDLETGKRWEHKSNERFPLS \& \& ILACANVLQRVDLGKERIDRVVRFSESNLVTYSPVTEKH $* \quad * * * * * *_{* *}^{*} * * *$ 130 164166

VG-SSITIENACEATMKT \& ITAANIVLKHIGGPQGVTAFLRL IGDKVTQLDWPELNQAKA

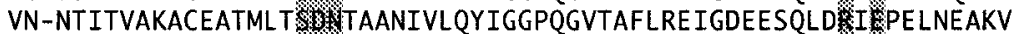
AS-QTTRIEHACEAAMLMS IITAANIVLRSIGGPRGVTTFLRSIGDKATRLD FFPRLNEANP VG-QAITLDDACFATMTT OIYAANI ILSAVGGPKGVTDFLRQIGDKETRLD II PDLNEGKL VG-QAITLDDACFATMTTS 1 TAANIILSAVGGPKGVTDFLRQIGDKETRLDIIPDLNEGKL

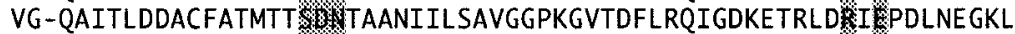
VAPDAMSWAQLCSAAVSY 3 ITAANL IARKLNGPQAVTQFLRDSGDTITRLD YY Y PELNSAIP LSPETVTFGKICQAAVSYS VGKKGMSLAELCQATLST OV SAANF ILQAIGGPKALTKFLRSIGDDTTRLDWWPELNEAVP

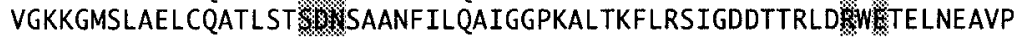

$$
179234
$$

DDLRYTTTPNAMNKTLYHILFEDVLAQNSKKQLKEWMQGTTVSDSLLRSVLPKGWSIADK GDLRUTTTPKAIVTTLNKLLLGDVLLDLDKNQLKTWMQNNKVSDPLLRSILPQGWFIAD \& A GDKRUTTTPNAMVNTLHTLLEGDALSYESRIQLKIWMQDNKVSDSLMRSVLPKGWSIAD GDLRMTTTPKAIASTLNQLLFGSTLSEASQKKLESWMVNNQVTGNLLRSVLPVKWSIADR GDLRATTTPKAIASTLNKLLFGSALSEMNQKKLESWMVNNQVTGNLLRSVLPAGWNIAD * * GDLRUTTTPKAIASTLNKFLFGSALSEMNQKKLESWMVNNQVTGNLLRSVLPAGWNIAD GDER STTPVAIAQTLNTLLLGNVLQPSSREQLMQWMRDDKVADGLLRSVLPDGWKIAD \& GDVRATTTPNAMVNSLRKILLGDALSASSRSQLTQWMLDDQVAGAL LRASLPSDWKIAD GDKR TTTPIAMVTTLEKLLIDETLSIKSRQQLESWLKGNEVGDALFRKGVPSDWIVAD K GDKR 聯TTTPIAMVTTLEKLLIDETLSIKSRQQLESWLKGNEVGDALFRKGVPSDWIVAD荻A

GANGSRGITAAIWTDEREPLIISIYLTQTNL SMPERNQVINEIGKAIFEEYAVK--- - 282 GGNGSRGITAML WHSERQPLIISIYLTETELAMAMRNEIIVEIGKLIFKEYAVK - - - 287 GGFGSRGITAMIWKENHKPVYISIYITETDLSLQARDQVIAQVSQLILDEYNTI--.- 283 GGFGARSITAIVWSEEKKTIIVSIYLAQTEASMAERNDAIVKIGRSIFEVYTSQSR-- 288 GGFGARSITAVVWSEHQAPIIVSIYLAQTQASMAERNDAIVKIGHSIFDVYTSQSR - - 288 GGFGARSITAVVWSEHQAPIIVSIYLAQTQASMAERNDAIVKIGHSIFDVYTSQSR-- 288 GDNGSRSIVSVVWPTSQKPLLVVIYITQTPATMAQRDAAIVRIGESLFSTLAVYD-- - 300 GGYGSRSIVAVIWPPSKQPLVVGIYITQTKASMQASNQAIARIGVVLKDTVAP-.-- 304 GGYGSRAITAVMWPPNRKPIVAALYITETDASFEERNAVIAKIGEQIAKTVLMENSRN 298 GGYGSRAITAVMWPPNRKPIVAALYITETDASFEERNAVIAKIGEQIAKTVLMENSRN 298

FiguRE 3.-Amino acid sequence alignments of the ampicillin resistance gene from Photobacterium damselae subsp. piscicida and class A $\beta$-lactamases from nine other bacteria. The sequences are indicated by their accession numbers as follows (the percentages in parentheses are the amino acid identities with the $P$. damselae subsp. piscicida ampicillin resistance gene): AB083415, $P$. damselae subsp. piscicida ampicillin resistance gene (100\%); BAA89386, Vibrio marinus $\beta$-lactamase (63\%); AAF23817, V. harveyi $\beta$-lactamase (56\%); AAD19217, V. cholerae $\beta$-lactamase (49\%); AAB 19430, Pseudomonas aeruginosa $\beta$-lactamase (48\%); AAK02055, Salmonella typhimurium $\beta$-lactamase (48\%); AAL85333, Citrobacter diversus $\beta$-lactamase (41\%); AAC09015, Aeromonas hydrophila 

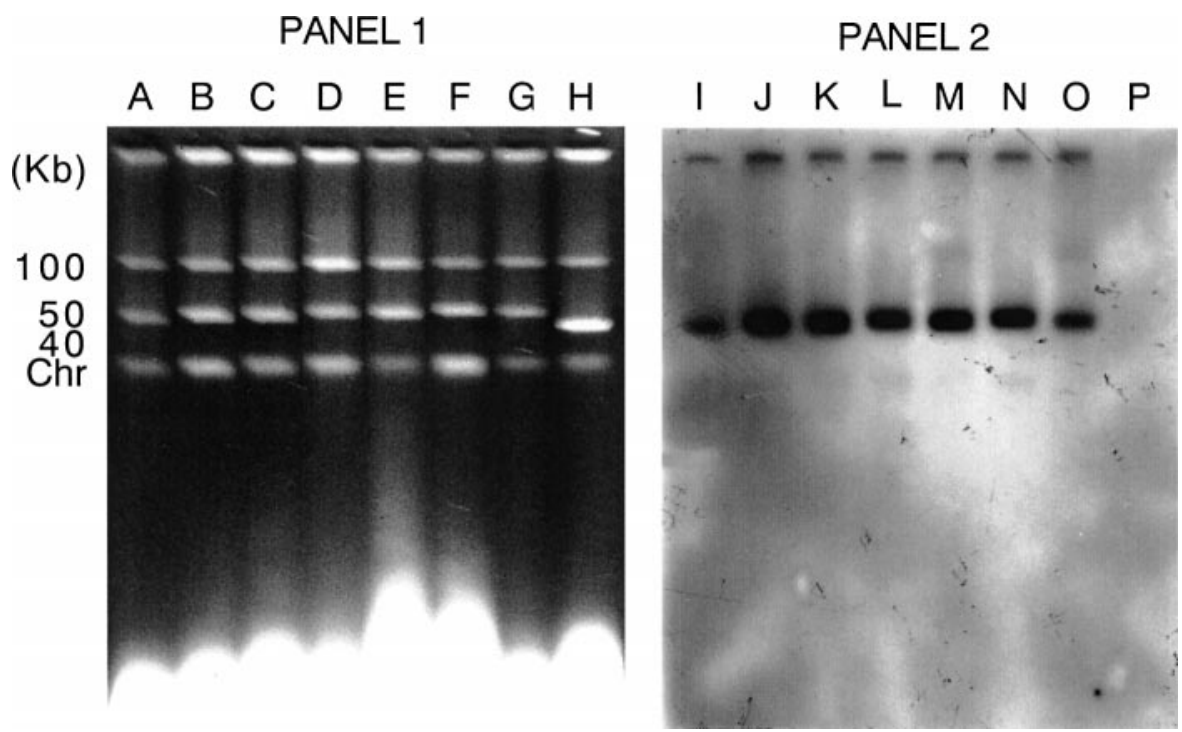

FIGURE 4.- Southern blot of a hybridization of a digoxigenin-labeled pPDP8517 ampicillin-resistant gene (oligonucleotides) and an R plasmid transferred from Photobacterium damselae subsp. piscicida that were isolated from various districts of Japan. Panel 1 is an agarose gel electrophoretic profile of $\mathrm{R}$ plasmids in transconjugants that were selected with ampicillin (lanes $\mathrm{A}-\mathrm{G}$ ) or chloramphenicol (lane $\mathrm{H}$ ) in a mating assay. Panel 2 is an autoradiogram of a nitrocellulose filter blotted with the DNA in panel 1 and probed with a digoxigenin-labeled pPDP8517 ampicillin-resistant gene (oligonucleotides). Lanes A and I involve plasmid pPDP8517 (detected in Nagasaki in 1985 with the same probe), lanes B and J plasmid pPDP8803 (detected in Kagashima in 1988), lanes C and K plasmid pPDP8832 (detected in Kumamoto in 1988), lanes D and L plasmid pPDP8911 (detected in Nagasaki in 1989), lanes E and M plasmid pPDP9010 (detected in Nagasaki in 1990), lanes F and N plasmid pPDP9105 (detected in Kumamoto in 1991), lanes G and O plasmid pPDP9309 (detected in Nagasaki in 1993), and lanes $\mathrm{H}$ and P plasmid pPDP9105 (detected in Kumamoto in 1991). The abbreviation Chr stands for chromosomal DNA.

hybridization was detected for one strain, indicating the absence of the pPDP8517 ampicillin resistance gene in that strain. Hybridization also occurred at the $110-\mathrm{kb}$ plasmid but not at the 100 $\mathrm{kb}$ (see lanes $\mathrm{A}-\mathrm{H}$ and $\mathrm{I}-\mathrm{P}$ ) and 40-kb plasmids (see lanes $\mathrm{H}$ and $\mathrm{P}$ ).

\section{Discussion}

Previous papers (Mizuno 1988; Fukuda 1999) have shown that the susceptibility to ampicillin in $P$. damselae isolates from cultured diseased yellowtail has frequently varied from low to high during summer months when pseudotuberculosis occurred in fish. Moreover, the percentage of the isolates harboring resistance to ampicillin has de- creased during the past 10 years (Mizuno 2002; Fukuda 2003), from $64 \%$ in $1990-1992$ to $3 \%$ in 1999-2001 (Fukuda 2003), implying that ampicillin has been effective as a chemotherapy for diseased fish in recent years (Mizuno 2002). The same has not been found in many other cases of drug resistance, however (Fukuda 2003). These findings on fish farms are presumed to be associated with the instability of the conjugal transfer of the ampicillin resistance gene as described in the present study. It has been suggested, however, that the immediate causes of the decreased percentage are lack of contact with infected fish and the low populations in fish culture (Mizuno 2002).

Southern blot analysis of 41 other ampicillin-

\section{$\leftarrow$}

$\beta$-lactamase (41\%); BAA02496, Proteus mirabilis $\beta$-lactamase (40\%); and AAF61417, Acinetobacter anitratum $\beta$ lactamase $(40 \%)$. Ambler's standard numbering of $\beta$-lactamases is used. The amino acid abbreviations are also standard; the numbers 70, 130, and so forth refer to nucleotide positions. Amino acid residues that were conserved in all cases are indicated by asterisks. Conserved amino acid regions that are important for the catalytic function of $\beta$-lactamases are shaded; signal peptide sequences are indicated in italics. 
resistant $P$. damselae isolates indicated that the pPDP8517 ampicillin resistance-like genes are located on the $50-\mathrm{kb}$ plasmids transferred from the $40 P$. damselae strains isolated from yellowtail farms in various areas and years. These results suggest that the identical ampicillin resistance gene is widely distributed among marine fish farms of the Kyushu area in Japan. We have no idea, however, of the actual prevalence of the ampicillin resistance gene throughout the fish farms.

In class A $\beta$-lactamases, a lysine residue at position 234 is conserved on most known sequences but an arginine residue has been found in a few such $\beta$-lactamases (Matagne and Frere 1995). An arginine residue at position 234 has also been found in class A $\beta$-lactamases from seven of nine strains with high identities as compared with the sequence of the pPDP8517 ampicillin resistance gene. The ampicillin resistance gene had a conserved RSG triad at position 234-236, as expected for some class A genes (Ambler 1980; Ambler et al. 1991). Moreover, the gene was present at an STFK active-site tetrad at position $70-73$ and a SDN loop characteristic at position 130-132 or the unique glutamic acid residue at position 166. Consequently, four important structural features conserved in class A $\beta$-lactamases (Ambler 1980; Matagne and Frere 1995) were present in the deduced amino acid sequence of the pPDP ampicillin resistance gene. In contrast, the amino acid residues conserved in the aligned sequences were not found among the amino acid sequence of the $P$. damselae ampicillin resistance gene and the sequences of the class B, C, and D $\beta$-lactamases. Nevertheless, the deduced amino acid sequence of the pPDP ampicillin resistance gene had from $63 \%$ to $40 \%$ identities among class A $\beta$-lactamases from bacteria other than $P$. damselae. These results suggest that the pPDP ampicillin resistance gene is a plasmidencoded class A $\beta$-lactamase and a novel class A gene.

In this study, we cloned an ampicillin resistance gene from a $50-\mathrm{kb}$ plasmid of $P$. damselae. Escherichia coli JM83 cells harboring a recombinant plasmid (pHSG398, which has a fragment of pPDP8517) had a highly elevated level of resistance to ampicillin $(>100 \mu \mathrm{g} / \mathrm{mL})$ compared with that of the host strain $(<3.1 \mu \mathrm{g} / \mathrm{mL})$, indicating that the cloned insert from the $P$. damselae plasmid contained an ampicillin resistance gene. Earlier studies had concluded that ampicillin resistance in P. damselae was chromosomal (Takashima et al. 1985; Kim and Aoki 1993), but Takashima et al. (1985) reported one case of ampicillin resistance being harbored by a plasmid. Our study is the first report of a $\beta$-lactamase gene isolated from $P$. damselae. Future work will involve determining the flanking sequences of the gene and the genetic mechanisms of ampicillin resistance transfer as well as the biochemical characterization of the protein.

\section{References}

Ambler, R. P. 1980. The structure of $\beta$-lactamases. Philosophical Transactions of the Royal Society of London B 289:321-331.

Ambler, R. P., A. F. Coulson, J. M. Frere, J. M. Ghuysen, B. Jaurin, B. Joris, R. Levesque, G. Tiraby, and S. G. Waley. 1991. A standard numbering scheme for the class A $\beta$-lactamases. Biochemical Journal 276: 269-272.

Fukuda, Y. 1999. [Diseases of marine fishes and shellfishes cultured in Oita prefecture and diagnosed from 1980 to 1997]. Bulletin of Oita Institute of Marine and Fisheries Science 2:41-73. (In Japanese.)

Fukuda, Y. 2003. [Drug susceptibility of fish-pathogenic bacteria isolated from cultured marine fishes in Oita prefecture from 1990 to 2001]. Bulletin of Oita Institute of Marine and Fisheries Science 4:25-50. (In Japanese.)

Fukuda, Y., S. Matsuoka, Y. Mizuno, and K. Narita. 1996. [Pasteurella piscicida infection in cultured juvenile Japanese flounder]. Fish Pathology 31:3338. (In Japanese.)

Grosa, J. H., M. E. Tolmasky, L. A. Actis, and S. Falkow. 1994. Plasmids. Pages 365-386 in P. Gerhardt, R. G. E. Murray, W. A. Wood, and N. R. Krieg, editors. Methods for general and molecular bacteriology. American Society for Microbiology, Washington, D.C.

Haeggman, S., S. Lofdahl, and L. G. Burman. 1997. An allelic variant of the chromosomal gene for class A $\beta$-lactamase K2, specific for Klebsiella pneumoniae, is the ancestor of SHV-1. Antimicrobial Agents and Chemotherapy 41:2705-2709.

Hanahan, D. 1983. Studies on transformation of Escherichia coli with plasmids. Journal of Molecular Biology 166:557-580.

IUBMB (International Union of Biochemistry and Molecular Biology). 1992. Enzyme nomenclature 1992. Academic Press, San Diego, California.

Iyobe, S., H. Sagai, and S. Mitsuhashi. 1981. Tn2001, a transposon encoding chloramphenicol resistance in Pseudomonas aeruginosa. Journal of Bacteriology 146:141-148.

Iyobe, S., M. Tsunoda, and S. Mitsuhashi. 1994. Cloning and expression in Enterobacteriaceae of the extended-spectrum $\beta$-lactamase gene from a Pseudomonas aeruginosa plasmid. FEMS Microbiology Letters 121:175-180.

Japanese Society of Chemotherapy. 1981. [The revised standard method for determining MIC (minimal inhibitory concentration)]. Chemotherapy 29:76-79. (In Japanese.) 
Joris, B., P. Ledent, O. Dideberg, E. Fonze, J. LammotteBrasseur, J. A. Kelly, J. M. Ghuysen, and J. M. Frere. 1991. Comparison of the sequences of class A $\beta$-lactamases and of the secondary structure elements of penicillin-recognizing proteins. Antimicrobial Agents and Chemotherapy 41:2294-2301.

Kado, C. I., and S. T. Liu. 1981. Rapid procedure for detection and isolation of large and small plasmids. Journal of Bacteriology 145:1365-1373.

Kim, E., and T. Aoki. 1993. Drug resistance and broad geographical distribution of identical R plasmids of Pasteurella piscicida isolated from cultured yellowtail in Japan. Microbiology and Immunology 37: 103-109.

Kubota, M., M. Kimura, and S. Egusa. 1970. [Studies on bacterial pseudotuberculosis in cultured larval yellowtail, I. Symptoms of a disease and pathological histology.] Fish Pathology 4:111-118. (In Japanese.)

Kusuda, R., and K. Inoue. 1976. [Studies on the application of ampicillin for pseudotuberculosis of cultured yellowtails, I. In vitro studies on sensitivity, development of drug resistance, and reversion of acquired drug resistance characteristics of Pasteurella piscicida]. Bulletin of the Japanese Society of Scientific Fisheries 42:969-973. (In Japanese.)

Lederberg, E. M., and N. Cohen. 1974. Transformation of Salmonella typhimurium by plasmid deoxyribonucleic acid. Journal of Bacteriology 119:10721074.

Matagne, A., and J.-M. Frere. 1995. Contribution of mutant analysis to the understanding of enzyme catalysis: the case of class A $\beta$-lactamases. Biochimica et Biophysica Acta 1246:109-127.

Mizuno, Y. 1988. [The latest tendency and the control measure of pseudotuberculosis in cultured yellowtail]. Fish Culture 25:82-85. (In Japanese.)

Mizuno, Y. 2002. [The pseudotuberculosis in fingerling yellowtail in the present and past]. Fish Culture 39: 74-77. (In Japanese.)

Morii, H., N. Hayashi, and K. Uramoto. 2003a. Cloning and nucleotide sequence analysis of the chloramphenicol resistance gene on conjugative $\mathrm{R}$ plasmids from the fish pathogen, Photobacterium damselae subsp. piscicida. Diseases of Aquatic Organisms 53: 107-113.
Morii, H., I. Nishibata, Y. Tutui, K. Uramoto, K. Kanai, and M. S. Bharadwaj. 2003b. Conjugative transferability of drug resistance in the fish pathogen, Photobacterium damselae subsp. piscicida. Bulletin of the Faculty of Fisheries Nagasaki University 84 : 53-63.

Muroga, K., T. Sugiyama, and N. Ueki. 1977. Pasteurellosis in cultured black seabream (Mylio macrocephalus). Journal of the Faculty of Fisheries and Animal Husbandry Hiroshima University 16:17-21.

Naas, T., L. Vandel, W. Sougakoff, D. M. Livermore, and P. Nordman. 1994. Cloning and sequence analysis of the gene for a carbapenem-hydrolyzing class A $\beta$-lactamase, Sme-1, from Serratia marcescens S6. Antimicrobial Agents and Chemotherapy 38: 1262-1270.

Nakai, T., N. Fujiie, K. Muroga, M. Arimoto, Y. Mizuta, and S. Matsuoka. 1992. Pasteurella piscicida infection in hatchery-reared juvenile striped jack. Fish Pathology 27:103-108.

Ohnishi, K., K. Watanabe, and Y. Jo. 1982. Pasteurella infection in young black seabream. Fish Pathology 16:207-210.

Roberson, B. S. 1993. Bacterial agglutination. Pages 81-86 in J. S. Stolen, T. C. Fletcher, D. P. Anderson, B. S. Roberson, and W. B. van Muiswinkel, editors. Techniques in fish immunology. SOS Publications, Fair Haven, New Jersey.

Seoane, A., and J. M. Garcia Lobo. 1991. Nucleotide sequence of a new class A $\beta$-lactamase gene from the chromosome of Yersinia enterocolitica: implications for the evolution of class A $\beta$-lactamases. Molecular and General Genetics 228:215-220.

Takashima, N., T. Aoki, and T. Kitao. 1985. Epidemiological surveillance of drug-resistant strains of Pasteurella piscicida. Fish Pathology 20:209-217.

Teo, J. W. P., A. Suwanto, and C. L. Poh. 2000. Novel $\beta$-lactamase gene from two environmental isolates of Vibrio harveyi. Antimicrobial Agents and Chemotherapy 44:1309-1314.

Ueki, N., Y. Kayano, and K. Muroga. 1990. [Pasteurella piscicida infection in juvenile red grouper (Epinephelus akaara)]. Fish Pathology 25:43-44. (In Japanese.)

Yasunaga, N., K. Hatai, and J. Tsukahara. 1983. Pasteurella piscicida from an epizootic of cultured red seabream. Fish Pathology 18:107-110. 